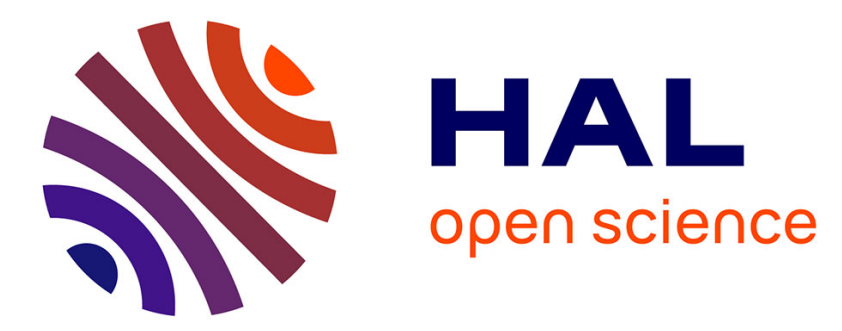

\title{
Research on Modeling of the RoHS Compliance System on UML
}

\author{
Xiao Ning Wang, Chuan Hong Zhou, Eynard Benoit, Zhao Xuan
}

\section{To cite this version:}

Xiao Ning Wang, Chuan Hong Zhou, Eynard Benoit, Zhao Xuan. Research on Modeling of the RoHS Compliance System on UML. Applied Mechanics and Materials, 2013, 336-338, pp.2529-2532. 10.4028/www.scientific.net/AMM.336-338.2529 . hal-01997639

\section{HAL Id: hal-01997639 \\ https://hal.utc.fr/hal-01997639}

Submitted on 17 Jan 2020

HAL is a multi-disciplinary open access archive for the deposit and dissemination of scientific research documents, whether they are published or not. The documents may come from teaching and research institutions in France or abroad, or from public or private research centers.
L'archive ouverte pluridisciplinaire HAL, est destinée au dépôt et à la diffusion de documents scientifiques de niveau recherche, publiés ou non, émanant des établissements d'enseignement et de recherche français ou étrangers, des laboratoires publics ou privés. 


\title{
Research on Modeling of the RoHS Compliance System on UML
}

\author{
Xiaoning Wang ${ }^{1, a}$, Chuanhong Zhou ${ }^{1, b}$, Eynard Benoit ${ }^{2, c}$ and Xuan Zhao ${ }^{1, d}$ \\ ${ }^{1}$ School of Mechatronic Engineering and Automation, Shanghai University; Shanghai Key \\ Laboratory of Mechanical Automation and Robotics, Shanghai 200072, China \\ 2 Department Mechanical Systems Engineering, Compiegne University of Technology, France

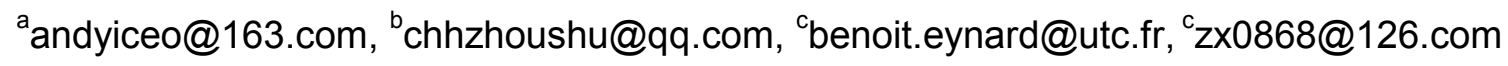

Key words: UML; ROHS; Product Lifecycle Management; conformity model; XMI

\begin{abstract}
With the application of the ROHS standard in the products management, the Product Overall Lifecycle Management has been increasingly complex. Based on the UML2.0 modeling technology, this paper discussed the ROHS conformity system modeling process by the modeling tool VP-UML. According to the information model, the core data about Product Life Cycle can be converted to the XMI document, and be used to get the optimization of the model.
\end{abstract}

\section{Introduction}

The goal of EU Green environmental protection instruction RoHS (Restriction of Hazardous Substances) is to eliminate six toxic substances in electronic and electrical products. Lack of basic theory and methods in RoHS conformity information management and product design in China results in that some enterprises can't deal with RoHS directive

Implementing intra-organizational RoHS compliance management system, which needs a feasible enterprise management system and integrate it into the PLM system, is a kind of feasible solutions. This paper adopts the mainstream visual modeling language-UML in order to ensure the structure of the system design good and the management system development quickly and efficiently. UML can play a considerable role in the software development with its good inheritance of the development process, life stage and implementation technology. This paper displays how to use UML2.0 for object-oriented analysis and modeling from the ROHS conformity model development process, with emphasis on Model building management process.

\section{System modeling with UML}

UML (Unified Modeling Language) is a kind of object technology support visual modeling language. Static modeling mechanism of UML includes use case diagram, class and object diagram, package diagram, construction diagram and layout diagram. Kinematic model of UML includes state diagram, sequence diagram, cooperation diagram and activity diagram [1].

\section{Use case diagram}

Use case diagram is used to describe system requirements which have user and case as two core elements from the user's point of view. User is the system-use and system-interactive object outside of the system [2]. Case is a group of description about action sequence including variable, the system implementing these actions, and generate observed results which transfer the value of specific participants. 


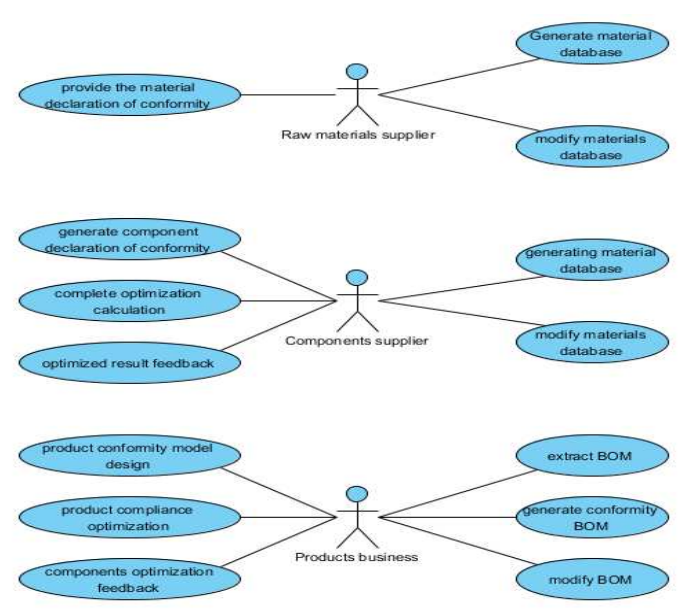

Fig. 1 The use case diagram of ROHS compliance system

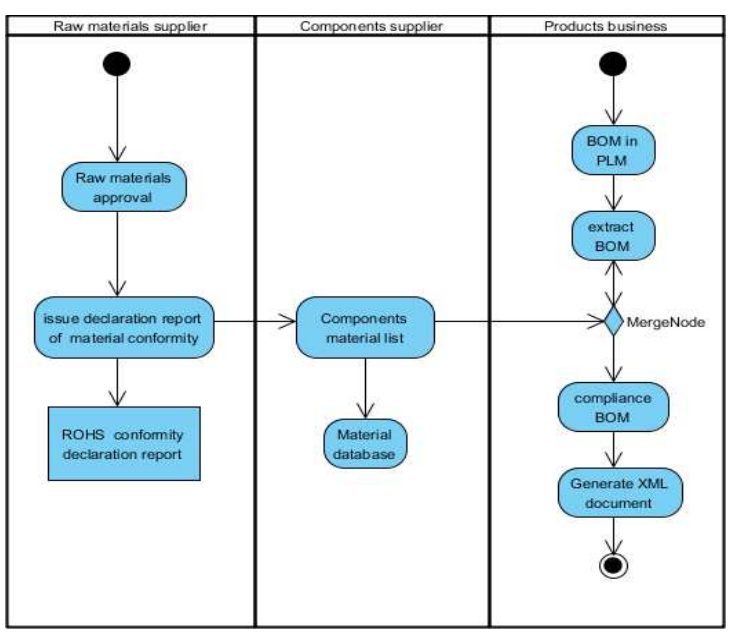

Fig. 2 The activity diagram of ROHS compliance system

As indicated in Fig. 1, the user (actor) is raw materials suppliers, components suppliers and Products business. Three main users complete the related operation of whole system. First, raw material suppliers need to provide the material declaration of conformity, generate material database and modify materials database. And the components business in the middle position needs to complete information interaction and provide product information management model. As the top, products business is mainly responsible for the product information optimization calculation and feed back the information to the downstream. In the final, optimal results and BOM have a integration and generating conformity BOM information.

\section{Activity diagram}

As shown in Fig .2 shows, this activity diagram use three lane to describe the role of business scope, the name of each lane on behalf of the business role, elliptic representative business activity, rectangular representative business entity. The specific business activity is: Material supplier will provide the materials to detection mechanism with professional appraisal qualification. If the test content to comply with relevant standards, a written proof can be deposited in the product database, in order to reference. Then components suppliers will integrate harmful material testing data into product material database, and uploaded to the product business PLM system. Product business then make BOM and material database combination, generate conformity BOM, and finally put it into the corresponding XMI file for later use optimized.

\section{Class diagram}

Description and management of the object are conducted with a mechanism of Class. First of all, search object from the problem domain determined by requirements, abstract into class and build relationships .And then analysis the interaction between objects around the cases and reconstruct the relationship among the objects [3]. Class diagram shows the static relationship between class (object), mainly including relevance, polymerization, generalization (inherit), etc. 


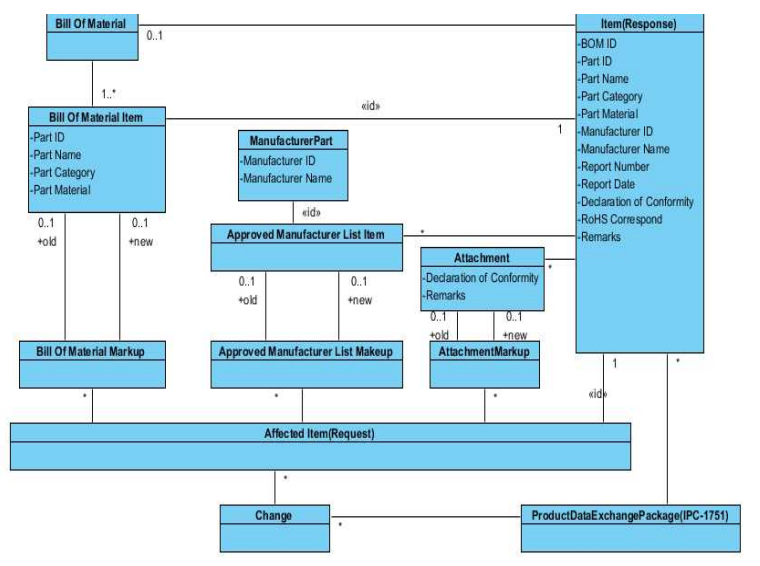

Fig. 3 ROHS compliance request response class diagram in IPC1751

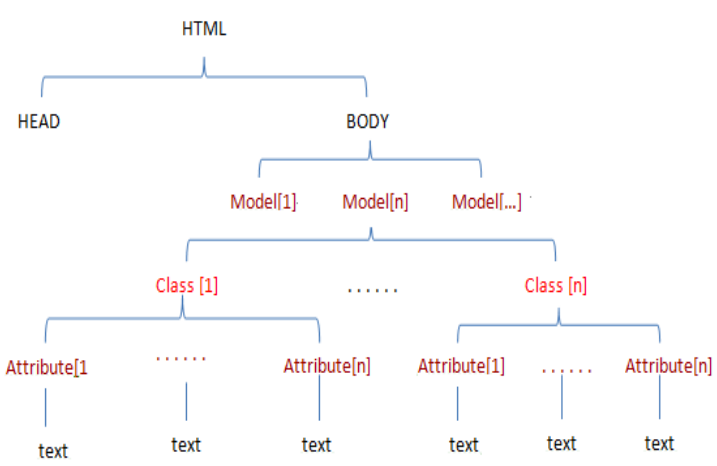

Fig. 4 The corresponding DOM tree of UML class diagram

In Fig. 3, the Class diagram contains mutual static relationship between several different types of class. The whole class diagram mainly display the information interaction process between Request party (Request) and Response party (Response). The whole process will follow the information standard from IPC - 1751 .

\section{XML of UML model}

In the UML modeling software, it offers a variety of operating mode with interoperability. The following is a meta-model class definition of "Substance":

$\leq$ ClassName="Substace"UserIDLastNumericValue="0"Root="false"QualityScore="92"QualityRe ason="1122"PmLastModified="2012-07-05T11:05:56.012"PmCreateDateTime="2012-05-09T21: 55:38.949"PmAuthor="Administrator"Leaf="false"Id="otxHjOyBOxiUSgmU"Documentation_plai $\underline{n=" \text { "BusinessModel="false" Abstract="false"Visibility="public"ConnectToCodeModel="1"Busines }}$ sKeyMutable $=$ "true" Active $="$ "false" $>$

In the above class diagram XMI document description, the source document is a direct modeling software conversion, so the text includes not only the direct description of class, but also the description of related class diagram. In data processing, this paper adopted the XML data file which is relatively simple for data processing. A system may contain many different models [4]. Each meta-model class is expressed by XML element: element name corresponding class name, elements definition listing the class attribute, the references of association end related to class and inner classes. The order of the attributes and the relationship does not make the request.

The XML document content is only a XML grammatical form description for class diagram which have limited help data concise effectiveness required for this article, so we need a reconversion to achieve this effect. Below is a XML file derived from content which can be found miscellaneous and low operable.

$-<$ Project Xml_structure $=$ "simple" UmlVersion="2.x"

TextualAnalysisHighlightOptionCaseSensitive ="false" Name="IPC1751" ExporterVersion="8.2.0" ExportedFromDifferentName="false" DocumentationType $=" h t m l "$

CommentTableSortColumn="Date Time" CommentTableSortAscending="false"

Author $="$ Administrator" $>$

$+<$ ProjectInfo $>$

\section{XSLT transformation on XMI document}

XSLT (eXtensible Stylesheet Language Transformation) is a part of W3C developing standard XSL (eXtensible Stylesheet Language), which is responsible for the conversion of the XML document. XSLT defines the conversion rules of the source tree and results tree corresponding part, namely 
template rule, which with the tag $<$ XSL: template $>$, can indicate that treatment of objects (element/attribute), the means of processing or conversion results. Rules will be instantiated, when meet document element of the root node in XSLT processor. From the DOM tree as shown in Fig. 4, the data are included in a table, so table, as anchor (namely positioning poi), can be expressed as the form of XPath expression.

The expression "HTML/body/model [n] / class [n]" specifies the path from the root $<$ HTML $>$ to anchor. According to the rules about XPath node information extraction, information will be stored in the selection rules library as XSLT file form. The rules specify how to retrieve the user information from XHTML document converted by the external program.

If we need to extract the subsidiary attribute and related text of Class[n] in Model [n], XSLT style-sheet can be written briefly as follow.

$<x$ sl:template match $=>>$

$<x s l:$ for - each select $=$ html $/$ body /model[n]/class[n]/modelchildren $>$

$<$ attribute $>$

$<x$ sl:value - of select $=$ attribute $[n] />$

$</$ attribute $>$

In the above style-sheets, it's just a simple attribute value extraction. We can use the same method of nested extraction to get add value under text. After determined the style sheet, the software will automatically convert it to the corresponding XML documents.

\section{Conclusions}

In the production of full life cycle of the product design, integration and optimization about product information is the key technology to reduce the redundancy of the product management and upgrade real-time interactive management of the product information at all levels of manufacturers. Using object-oriented visualization modeling technology to achieve information interaction at all levels of physical layer, simplify the model calculation complexity and achieve the optimization design real-time guidance of all manufacturer production process.

\section{Acknowledgement}

This work is supported by National Natural Science Foundation of China (No. 61073122).

\section{References}

[1] IBM Developers Works. IBM SOA Foundation: An architectural introduction and overview [EB/OL].(2012-10-15).http://www.ibm.com/developerworks/webservices/library/ws-soa-paper

[2] Medvidovic N, Rosenblum D S, etc. Modeling software architectures in the unified modeling language [J].ACM Transaction Software Engineering and Methodology, 2002, 11(1):p.3-57

[3] Object Management Group. Unified modeling language super structure specification, V2.0 [EB/O] .(2005-04-04)[2010-06-16]http://www.omg.org/docs/formal/05-07-04.pdf

[4] Lee J S, Lee K H. Computing simple and complex matching's between XML schema for transforming XML documents[J].Information and Software Technology, 2006, 48: p. 937-946. 